\title{
La Táctica macedónica en tiempos de Filipo II
}

\author{
JoRgE JUAN MORENO HERNÁNDEZ
}

\begin{abstract}
RESUMEN
Una de las claves del ascenso de Macedonia durante el siglo IV a.C. se centra en la superioridad del ejército y de las tácticas empleadas por Filipo II. Este monarca, tras llevar a cabo ciertas reformas militares, obtendrá una victoria tras otra hasta situarse a la cabeza de la Grecia Continental y los Balcanes. El objetivo del presente artículo es analizar cada una de las batallas de Filipo (aquellas en que disponemos de suficiente información), así como

la composición del ejército, para poder examinar en profundidad las tácticas desplegadas por el macedonio, que una y otra vez le condujeron a la victoria frente a los más potentes ejércitos de la época.
\end{abstract}

La aparición del ejército macedonio en Grecia y Asia supuso un profundo impacto en el ámbito militar de la época. Los ejércitos de Filipo y Alejandro fueron capaces de vencer en poco tiempo a los hasta entonces invencibles hoplitas o a las innumerables tropas de Darío. Se trataba de un ejército especializado y eficiente, caracterizado además por su fuerte espíritu nacional, equipado con un armamento superior y cuyo despliegue en combate recogió muchas de las enseñanzas griegas del periodo precedente. Durante la Guerra del Peloponeso y el siglo IV la combinación de infantería ligera, caballería e infantería pesada se había convertido en uno de los elementos fundamentales en la batalla. El estratego Demóstenes, los Diez Mil de la Anábasis, Ifícrates, Agesilao o Epaminondas son sólo algunos de los generales que lo llevaron a la práctica. En el caso de Macedonia, fue la integración de falangitas, hipaspistas y caballería lo que confirió una superioridad definitiva al ejército macedonio, y dio a cada elemento una importancia vital en el campo de batalla. 


\section{EL EJÉRCITO MACEDONIO}

La falange, junto a la caballeria, se convirtió pronto en la base del ejército nacional macedonio. Desconocemos el momento exacto en que se produjo el salto cualitativo entre el antiguo ejército macedonio, compuesto de infantería ligera de baja calidad, y aquel fruto de las reformas de $\mathrm{Fi}$ lipo, que se impondrá en Grecia y los Balcanes durante su reinado; no obstante, analizaremos la composición del mismo a medida que avancemos en el análisis de los enfrentamientos del reinado de Filipo'. El falangita de Filipo y Alejandro que conocemos por las fuentes estaba armado con sarisas, espadas y elementos de protección ligeros que incluian escudo, casco y protecciones de lino, a lo que habríamos de sumar su alta preparación y entrenamiento ${ }^{2}$. Dentro de la falange destaca el cuerpo de elite de los hipaspistas, tropas escogidas y equipadas de la misma manera que el resto de falangitas ${ }^{3}$, y que junto a la caballería macedónica formaron la punta de lanza del ejército. Tanto Alejandro como Filipo contaban además con abundante infantería ligera, que adquiere mayor importancia en Grecia durante este siglo, y que hasta la reforma militar y el surgimiento de la falange había sido la base de la infantería macedóni$\mathrm{ca}^{4}$. Filipo contaba también con la caballería más poderosa de la época, ya que no sólo disponía de la fuerza de los Compañeros, sino también de la caballería tesalia. Pese a que actualmente se debate sobre la capacidad de esta caballería a la hora de enfrentarse con una formación de infantería pesada que no hubiera perdido el orden (carga que hasta entonces ningún tipo de caballería habría osado realizar, ni siquiera la te-

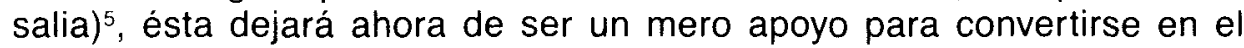

Diodoro, 16.3.1-3, es la primera fuente que recoge estos cambios, atribuyéndolos al comienzo de su reinado; esta información será matizada durante el presente articulo. Asimismo habriamos de tener en cuenta la incorporación de la Alta Macedonia tras la victoria frente a Bardilis del 358, ya que es incluida en el reino incrementando las cifras del ejército.

2 Para una mayor información sobre el armamento del falangita, véase: $M$. Andronikos, "Sarissa", $\mathrm{BCH}, 1970,94,91-107$; G.T. Griffith y N. G. L. Hammond, A History of Macedonia. Vol 2: 550-336 B.C., Oxford 1979, 405-27 (desde ahora HM II); Hammond, Alejandro Magno. Rey, general y estadista, Madrid 1992, 56-63; Hammond, “A Macedonian shield and Macedonian meassures", ABSA 91, 1993, 365-66; G.T. Gritfith, "Philip as a general and the Macedonian army», en Hatzopoulos y Loukopoulos (eds.) Philip of Macedon, Atenas 1980, 58-77; A. M. Snodgrass, Arms and armours of the Greeks, Londres 1967, 120121; P. Ducrey, Warfare in Ancient Greece, Nueva York 1986, 79-103; M.M. Markle, "The Macedonian sarissa, spear and related armour", AJA 81, 1977, 323-339; P.A. Manti, "The Cavalry Sarissa", AncW 8. 1983, 73-80, y "The Sarissa of the Macedonian Infantry", AncW 23.2, 1992, 31-42.

3 Tradicionalmente se pensaba que estos hipaspistas estaban armados de forma más ligera que los pezhetairoi (H. Berve, Das Alexanderreich auf prosopographischer Grundlage, Munich 1926, I, 25). Tarn fue el primero en poner de manifiesto que su equipamiento era exactamente el mismo (Alexander the Great, Cambridge 1979, II, 153f.), y Griffith completará dicha teoría (HM II, 417); no obstante, hay autores que, frente a esta opinión generalizada, sostienen que estos hipaspistas estarian armados con panoplias hoplíticas (H. Delbruck, History of the art of War: Within the framework of Political History, vol. 1: Antiquity, reedición de Londres 1975, 179; M.M. Markle, "The Macedonian Sarissa, spear and related armour", AJA 81 1977, 329, y "Use of Sarissa by Philip and Alexander of Macedon", AJA 82, 1978, 483-97; R.D. Milns, "The Hipaspist of Alexander the Great: some problems", Historia 20, 1971, 187).

4 Tuc. 2.100.5, 4.79, 82-83, 124; Jen. Hel. 5.2.11-24, 37-43, 3.1-6, 8-9, 18-20, 26, 40; D.S. 15.19-23.

5 Op. cit. n. 10. 
arma ofensiva por excelencia: era capaz de golpear con gran velocidad alli donde surgían huecos o en los flancos del enemigo, y demostró su superioridad frente a la caballería enemiga en todos los enfrentamientos de que tenemos constancia. La formación y el entrenamiento que recibía esta caballería de los Compañeros eran muy elevados ${ }^{6}$; en cuanto al armamento, destaca tanto el elemento defensivo (formado por corazas o corseletes, y cascos de tipo tesalio normalmente) ${ }^{7}$, como el elemento ofensivo, compuesto en buen número de ocasiones por lanzas de caballería superiores en tamaño a las del resto de la caballería, e incluso a las de infantería: se

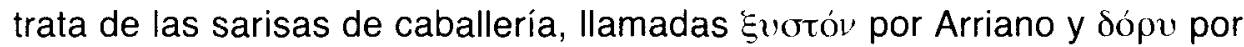
algunas fuentes, inferiores en tamaño a las sarisas de infantería pero mayores al resto de las armas, lo que potenciaba su carácter ofensivo ${ }^{8}$. Asimismo, la formación en cuña que adoptó la caballería macedónica en tiempos de Filipo y Alejandro nos hace pensar en una disposición agresiva y con capacidad de penetración en las filas enemigas ${ }^{9}$. Existe cierto debate en torno a las posibilidades de esta caballeria, en especial en lo concerniente a la carga directa contra una falange hoplítica ${ }^{10}$. En nuestra

6 Ya en su juventud los hijos de la aristocracia macedónica se ejercitaban en la monta, a la edad de catorce años muchos de ellos entraban en el Cuerpo de Pajes del rey, a los dieciocho concluyen este entrenamiento y pasan a formar parte de los guardaespaldas del rey. Finalmente pasaban a convertirse en ¿т « p \%, Compañeros del rey. Para más información en cuanto a dicha preparación y los Pajes Reales, consultar Hammond (1990) «Royal pages, personal pages and boys trained in the Macedonian Manner during the period of the Temenid Monarchy", Historia 39, 261-289.

7 Gritfith, HM II, 417, opina también que la caballería macedónica pudo estar equipada además con un escudo ligero, si bien no es la tendecia general.

8 Estamos de acuerdo con la teoria de P.A. Manti (1983) "The Cavalry Sarissa", AncW. 8, 73-80, según la cual es muy posible que las fuentes simplemente recogieran la presencia de esta lanza de caballería de grandes dimensiones con diferentes nombres, y que fuera el arma básica tanto de los sarisoforoi como de los Compañeros. No obstante, la caballería podría estar armada con lanzas de caballería normales (inferiores en tamaño), o con jabalinas, de acuerdo con las circunstancias, como podemos leer en las campañas de Alejan-

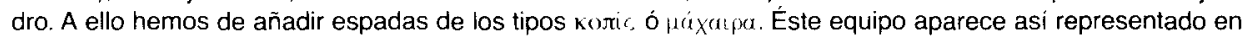
el Mosaico de Alejandro, en el Sarcótago de Alejandro y en el fresco de la Tumba de Naoussa. A. M. Snodgrass (1967), Arms and armours of the Greeks, Londres, 120-121; Griffith HM II, 411-14

9 De acuerdo con Elio Táctica 18.4, fue Filipo quien introdujo esta formación en la caballeria macedó. nica. Seguramente tomó esta formación de tracios y escitas, al ser más efectiva que el cuadro (Asclepiódoto Tact. 7.3, Eliano Tact. 18.4). Asimismo, es posible que los corceles de la caballería pesada estuvieran equipados con algún tipo de petos o testeros ligeros, lo que potenciaba su fuerza en el choque: un par de ejemplos de estos elementos los podemos contemplar en P. Connolly (1981), Greece and Rome at War, Londres, p. 73, pl. 1-2.

10 Para un análisis de la situación y la viabilidad de este tipo de ataque, véase J.J Moreno, "La caballeriamacedonia: teoría y práctica", Gladius 24, 2004. El profesor Minor M. Markle (AJA 81, 1977, 338), partiendo de algunas de estas premisas, se muestra de acuerdo con la posibilidad de que la caballeria macedónica pudiera efectuar cargas directas contra infantería pesada de línea, e incluso afirma que esta formación en cuña era utilizada por Filipo para abrir las formaciones griegas. Sin embargo, debemos recordar que en estos momentos los caballos no poseen herraduras, ni los jinetes silla de montar o estribos, lo que hacia de la monta algo harto dificil, y más en una carga de tales características. Esta es la principal razón por la que algunos autores descartan tal opción. Véase W.W. Tarn, Hellenistic Military and Naval Developments, Cambridge 1930, 62; Santosuosso, Soldiers, Citizens and the symbols of War, Oxford y Colorado 1997, 120; N. G. L. Hammond, "Alexander's charge in the Battle of Issus in 333 B.C.", Historia 41, 1992, 401-402; F.E. Adcock. The Greek and Macedonian Art of War, Berkeley 1957, 50-51; J.K. Anderson, Ancient Greek Horsemanship, Berkeley 1961, 128-30. Pese a elio, y como señala P.A. Rahe, "The annihilation of the Sacred Band", AJA 85, 1981, 85: "To the best of my knowledge, no ancient historian has explained why the phalanx could withstand cavalry assault". 
opinión, es más probable que la caballería macedónica contara con el apoyo de su propia infantería a la hora de enfrentarse a la infantería pesada, en cuyo caso tendría más posibilidades de imponerse al aprovechar la debilidad del enemigo y el apoyo de la infantería.

Como venía imponiéndose durante el siglo IV, cada uno de los cuerpos del ejército debía actuar en connivencia con el resto, complementándose unos a otros. Así, en algunas de las batallas de Filipo y Alejandro, la infantería de falange presentaba batalla con sus sarisas, mientras la caballería asestaba el golpe en algún flanco o aprovechaba los huecos surgidos merced a la presión de la propia infantería ${ }^{11}$. Esta combinación de tropas y una sabia dirección del ejército darán a Filipo y Alejandro la mayoría de sus victorias. Asimismo, éstos se servían de la alta preparación y veteranía de sus tropas tanto en el combate como fuera de é $\left.\right|^{12}$.

Otro punto fundamental en la táctica de Filipo primero y Alejandro después será la concentración de tropas en uno de los flancos, el cual debia asestar el golpe definitivo sobre el ejército enemigo. La influencia de Epaminondas y su orden oblicuo es más que evidente. Sin embargo, los ejércitos de Filipo y Alejandro ofrecian un mayor número de posibilidades que los ejércitos griegos, ya que los puntos fuertes macedonios no se limitaban a la infanteria pesada (la de los hoplitas en el caso de los griegos, la de los falangitas macedonios en el caso de Filipo y Alejandro), sino también a la caballería macedónica y tesalia. Así, en un buen número de ocasiones este golpe fue asestado por medio de la caballeria y de los hipaspistas, que además servían de nexo con el resto de la falange. Finalmente, las persecuciones tras la victoria daban el mazazo definitivo a las descompuestas fuerzas enemigas. Veamos ahora las principales batallas del ejército macedonio en tiempos de Filipo, para ejemplificar lo dicho.

\section{LAS BATALLAS}

En 358, dos años después de su ascenso al trono, Filipo se encontraba en una situación crítica. Tras adiestrar a sus tropas y obtener las primeras victorias frente a Argeo y frente a los peonios, se dirige contra el rey ilirio Bardilis a las regiones montañosas de la Alta Macedonia ${ }^{13}$. Filipo reclutó un ejército con todos los efectivos posibles, hasta un total de diez mil infantes

11 Pese a tener un papel de menor importancia en las grandes batallas, no hemos de olvidar a la infantería ligera, encargada en muchos casos de proteger los flancos de la menos maniobrable falange (cuya formación rígida ponía al descubierto su flanco y retaguardia, así como de abrir el ataque en la mayor parte de las batallas, como venía ocurriendo en el resto de Grecia.

12 Sirvan como ejemplo las veloces y largas marchas de los ejércitos macedonios tanto en Asia como en Europa (caso de la campaña de Anfisa de Filipo, que veremos posteriormente), o las complicadas maniobras ejecutadas durante el combate (en Queronea, por ejemplo, que también veremos).

13 Sobre el reclutamiento de un nuevo ejército: D.S. 16.2.6; sobre el incidente de Argeo y los atenienses: 16.3.5f.; sobre la campaña contra los peonios: 16.4.2. 
y seiscientos jinetes, frente a los quinientos jinetes y diez mil infantes escogidos del ilirio ${ }^{14}$. Consciente de la inferioridad de su caballería, Bardilis dispuso a su infantería en cuadro para evitar así ser flanqueado por la caballería enemiga, mientras Filipo, al recibir la iniciativa del combate y contemplar que en el centro ilirio se situaban mejores tropas que en los laterales, concentró «lo mejor de su infantería» en el flanco derecho ${ }^{15}$, suponemos que dejando la izquierda y el centro retrasados (en orden oblicuo). El texto es el siguiente:

"Cuando los ejércitos se aproximaron el uno al otro y chocaron con gran estruendo, Filipo, al mando de lo mejor de sus macedonios en el flanco derecho, ordenó a su caballería cabalgar más allá de las filas de los bárbaros y cargar contra los flancos, mientras él mismo, cayendo sobre el enemigo, inició un enconado ataque. Pero los ilirios, formando en cuadro, entraron en el combate con valentía. Al principio la batalla estaba indecisa, dado el valor demostrado por ambos bandos... pero al final, en cuanto apareció la caballería por los flancos y la retaguardia, y Filipo con lo mejor de sus tropas combatiendo con gran heroísmo, la gran masa de los ilirios se batió en retirada» ${ }^{16}$.

Podemos tratar de reconstruir este fragmento a partir de los ligeros retazos de que disponemos. En primer lugar parece que Filipo eligió el terreno, ya que en las fuentes se dice primeramente que Bardilis fue hacia él, confiado seguramente tras su anterior victoria sobre Pérdicas; ello nos permite suponer la elección de una llanura apta para su caballería, superior a la enemiga, asi como para el hipotético despliegue de su falange (opción que no podemos descartar del todo). A medida que se acercaban ambos ejérci-

${ }^{14}$ D.S. 16.2.4-5. El reclutamiento de un ejército de tal tamaño debió suponer un duro esfuerzo para Filipo, ya que hacia menos de dos años que Bardilis habia derrotado a su hermano Pérdicas, dando muerte a éste y a cuatro mil macedonios (cifra realmente elevada para la Macedonia del momento). Durante cerca de cuarenta años Bardilis y su ejército ilirio demostró una enorme superioridad en los Balcanes, derrotando no sólo a los macedonios en repetidas ocasiones, sino también a los molosos, a los que causó un enorme número de bajas. Una de las causas de sus superioridad fue la adopción parcial de la panoplia hoplitica y sus tácticas antes que sus oponentes (Diodoro, en 15.13.2, menciona que Dionisio de Siracusa concedió quinientas panoplias hoplíticas a sus aliados ilirios hacia el 385).

15 D.S. 16.4.5-6. Se cree que Frontino Strat. 2.3.2, está hablando también de este enfrentamiento, en el que aparece Filipo frente a un ejército ilirio que parece formar en cuadro. De acuerdo con Hammond, "Macedonia before Philip and Philip's first year in battle", Meditarch 7, 1994, 15, y "Training in the use of sarisas and its effects in battle, 359-333 B.C.". Antichthon 14, 1980, 58, etc., esta infanteria está ya armada con sarisas. Frente a la opinión de Markle (1978), p. 486. En nuestra opinión, si es posible que parte de su ejército estuviera armado con este tipo de lanzas y dispuesto en formación, asi como el hecho de que fueran las tropas escogidas que rodeaban al rey en la batalla y que habria heredados de su hermano, los encargados de asestar el golpe macedonio sobre las fuerzas ilirias al estar más preparados que el resto de la infantería macedónica; quizá éstos hubieran sido entrenados ya en el combate en falange como hoplitas o directamente como falangitas macedonios, más probable. Hammond habla también de "guardia del rey", conocidos también como "guardia de los macedonios" (Hammond, MedArch 7, 15), los cuales, en nuestra

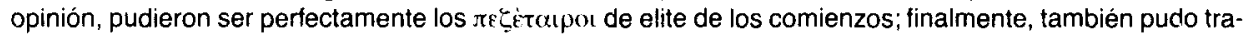
tarse de la infantería que habia estado bajo sus órdenes con anterioridad a la muerte de su hermano, y que habria combatido bajo su mando en alguna de las regiones del Este de Macedonia defendiendo las fronteras: Espeusipo FHG 4.356 F1; Griffith HM II, 2061.; Hammond, Philip of Macedon, Londres 1994, 18.

16 D.S. 16.4.2-7; véase también Frontino Strat. 2.3.2. 
tos, Bardilis modificó sus líneas y adoptó una formación en cuadro, de forma que su infantería pudiera hacer frente a la caballería macedónica sin verse sorprendida en los flancos o la retaguardia; sin embargo esta formación implicaba un desplazamiento lento y dificultoso, y cedía la iniciativa al contrario. Al frente del flanco derecho, Filipo avanzó con sus mejores infantes contra la esquina del cuadro ilirio, dejando al resto del ejército ligeramente retrasado ${ }^{17}$. Mientras, la caballería en masa pasaba al lado de Filipo con la orden de cargar en el momento adecuado (suponemos que la cabaIlería iliria habría sido derrotada por la macedónica, o previamente retirada por Bardilis). Los infantes a las órdenes de Filipo golpearon el ángulo izquierdo de la formación, donde se concentraban tropas ilirias de peor calidad $^{18}$, además de ofrecer la posibilidad a Filipo de concentrar una mayor cantidad de tropas sobre un punto más aislado y peor defendido, con lo que consiguió seguramente romper el cuadro o al menos abrir huecos en sus líneas. Mientras la infantería gira contra las líneas enemigas, la caballería rápidamente aprovechó para atacar utilizando su potencia en zonas ahora menos defendidas, así como para cargar los flancos que pudieron ofrecer los ilirios. Ante el ataque combinado de infantería por el frente y caballeria en los flancos y las brechas, los ilirios derrotados progresivamente debieron caer sin duda en la confusión y huyeron en desbandada ${ }^{19}$. Las tropas macedónicas los persiguieron durante un largo trecho, causando un gran número de bajas ${ }^{20}$.

Filipo consiguió una victoria aplastante tan sólo dos años después de la debacle de su hermano Pérdicas, lo que indica en cierto modo que se habia producido un cambio profundo en el ejército macedonio. Las claves de dicho

17 Filipo conduce a los hombre "mejores" 0 “más fuertes", lo que nos permite pensar en el cuerpo de infantería que servia como cuerpo de guardia real que aparece ya en Teopompo: «hombres escogidos de entre todos los macedonios, los más altos y más fuertes, servían como Guardias del Rey y fueron llamados

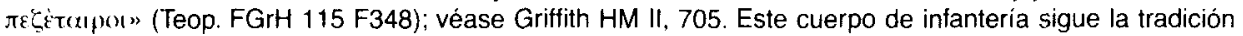
baicánica de crear cuerpos de elite alrededor del monarca, y que parece que en el caso macedonio debemos al hermano mayor de Filipo, Alejandro II. Esta teoria es seguida por Tarn, Alexander... I, 141; A.B. Bosworth, "Asthetairoi", CQ 26, 245; Hammond, Philip... 18-19; R.D. Milns, «The army of Alexander the Great», en O. Reserdin (ed.), Alexandre le Grand. Image et Realité. Entreticus sur l'Antiquité Classique. Foundation Hardt vol. 22, Ginebra 1976, 90-96. Por el contrario, A. Momigliano sostiene que es Alejandro l el que origina dicho cuerpo, en Filippo it Macedone. Sagio sulla storia greca del IV secolo a.C., Milán 1987 (reed.), 8-11.

18 De acuerdo con Frontino 2.3.2, lo mejor del ejército ilirio se encontraba en el centro, mientras que los laterales los ocupaban tropas de peor calidad, que además eran el punto de unión con el resto.

19 Toda esta reconstrucción es aceptada en sus líneas fundamentales por la mayoria de los historiadores. Hammond, Philip... 25-28; Griffith HM II, 203-4; A.B. Lloyd «Philip II and Alexander the Great: the Moulding of Macedon's Army", en A.B. Lloyd (ed.), Battle in Antiquity, Londres 1996, 189.

${ }^{20}$ D.S. 16.4.5-6. La mayor parte de las bajas en la antigüedad se producian durante las persecuciones de los ejércitos que huian. No obstante, la cifra de siete mil bajas en las líneas ilirias que nos da Diodoro resulta sorprendente. Sin duda fue causa de una dura persecución de la intanteria macedónica junto a la caballeria. Para una aproximación a la cantidad de bajas que se producian en los enfrentamientos clásicos, véase P. Krentz, "Casualties in hoplite battles", GRBS 26, 13-20, donde realiza un buen estudio sobre la cantidad aproximada de bajas en los ejércitos hoplíticos; sin embargo, dichos ejércitos carecian en buena parte de una cabaliería potente, y las persecuciones eran más limitadas. Las violentas y férreas persecuciones de Filipo y Alejandro aumentaron sobremanera la cantidad de bajas en las filas enemigas, a la vez que minaban la fuerza del rival derrotado y aumentaban la importancia del factor psicológico anterior a la batalla. 
cambio aparecen sutilmente en las fuente ${ }^{21}$ : las exhortaciones de Filipo en la Asamblea dirigidas a restaurar la moral de su ejército, la reorganización de sus unidades, las continuas maniobras y el entrenamiento de sus soldados, y un armamento apropiado y novedoso (quizá ya el armamento de la falange macedónica, como sugiere Diodoro ${ }^{22}$, al menos para cierta parte del ejército, si bien creemos que los cambios de Filipo se produjeron tras un periodo de experimentación dilatado). Markle sostiene que el ejército macedonio estaba armado con panoplias hoplíticas, pero ello habría supuesto un esfuerzo desmesurado e inalcanzable para el reino macedonio, compuesto mayoritariamente por una clase agrícola-ganadera de escasos medios, lo que sumado a la crítica situación de Macedonia (que duraba ya más de una década), nos permite descartar dicha hipótesis: sin duda Filipo no pudo aceptar los costos de unas panoplias tan costosas como las hoplíticas (no así las macedónicas) ${ }^{23}$. Junto a los cambios en el interior del ejército, quizá todavia en ciernes, destaca la aparición de un general como Filipo, inteligente y carismático, que aplicó pronto las lecciones de los tebanos en el campo de batalla como eran la concentración de tropas, el orden oblicuo, la prefiguración de la combinación de infantería y caballería, y la explotación de las mejores unidades del ejército ${ }^{24}$. Hay quien sostiene que no hubo nada excepcional en la disposición de las mejores tropas de Filipo en el ala derecha, y no sin razón ya que era la táctica común en Grecia ${ }^{25}$; pero en cuanto al uso de la caballería, que fue utilizada como fuerza de choque contra los flancos de la infanteria, sólo había sido puesto en práctica por Pelópidas en

${ }^{21}$ D.S. 16.3, Polieno 4.2.10, Frontino 4.1.6. Parece que todos ellos tienen una fuente común que es Éforo, de acuerdo con Hammond, The Macedonian State. Origins, Institutions and History, Oxford 1989,5 .

22 D.S. 16.3.1-3. Para Hammond (1989), 5, el armamento es el elemento crucial, compuesto especialmente por sarisa y pelte, lo que permitia un orden más compacto que el hoplítico, por lo que las palabras

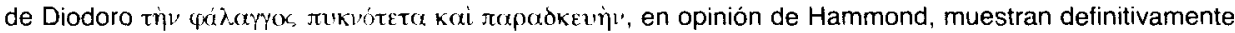
que fue la falange macedónica la que venció aquel día. Griffith apoya la teoria del temprano surgimiento de la falange macedónica: G.T. Griffith, "Philip as a general and the Macedonian Army", en Hatzopoulos y Loukopoulos (eds.) Philip of Macedon, Atenas 1980, 58-77, 59. Contra la opinión de Markle (1978), 486, que postula una aparición tardia de la misma, con posterioridad a Queronea.

${ }^{23}$ Markle (1978), 486-87, c.18, propone algunas soluciones en cuanto a los ingresos macedonios, dudosas e insuficientes a todas luces. Otro de los puntos de su argumentación es que Filipo no se habría arriesgado a poner en práctica sus reformas ya en su primer gran enfrentamiento; sin embargo el verdadero riesgo era no hacerlo, ya que la infanteria macedónica anterior era de baja calidad, y la posibilidad de haber experimentado con la falange macedónica se retrotrae al reinado de Pérdicas y posteriormente a su primer enfrentamiento frente a Argeo primero y a los peonios después; en cualquier caso, alguna tenia que ser la primera vez, y pudo haberlo utilizado como factor sorpresa contra los ilirios.

24 Las lecciones de Epaminondas y Pelópidas habian surtido efecto en el joven macedonio durante su estancia en la capital beocia. Para las innovaciones tebanas, véase: G. Cawkwell, "Epaminondas and Thebes", CQ 22 (1972), 254 ff.; J. Buckler, The Theban Hegemony 371-362 B.C., Cambridge, Massachusetts y Londres 1980; J. Pascual González, "Innovación y adaptación military griega en el siglo IVa.C.: el ejército tebano-beocio de la hegemonía". Actes del IXè Simposi de la Secció Catalana de la SEEC, Barcelona 1991. Una visión diferente es propuesta por V. Hanson «Epaminondas, the Battle of Leuctra (371 B.C.) and the Revolution in Greek Battle Tactics", ClAnt 7, 1988, $190 \mathrm{ff}$. Para la estancia de Filipo en Tebas, véase M. Sordi «ll soggiorno di Filippo a Tebe nella propaganda storiografica", Contributi dell Istituto di Storia Antica, Milán 1974, 58ff.; Griffith HM II, 181, 186 y 205; Aymard, REA 56, 1954, $15 f$.

${ }^{25}$ Véase Markle (1978), 486 
Cinoscéfala (364) y por Epaminondas en Mantinea (362) ${ }^{26}$. Asimismo, la combinación de caballería e infantería sobrepasó con creces a la tebana, y se convirtió en uno de los pilares de la superioridad macedónica en la bataIla. Pese a la opinión de Markle ("there seems to be no surprise in this battle, certainly no indication of the use of any new infantry tactics"), parece que lo que ocurre es todo lo contrario, ya que se ponen en práctica las tácticas tebanas de las que los ilirios poco sabrían, y resulta difícil creer que un ejército experimentado como el ilirio (Diodoro dice que su ejército estaba compuesto por "hombres selectos"), con una moral alta y que contaba al menos con un cuerpo de hoplitas, fuese vencido por el tradicional ejército macedonio compuesto por una infantería ligera de baja calidad y un cuerpo de caballeria de elite, que había sido derrotado severamente tan sólo dos años antes (lo que sin duda debió influir en la moral macedónica) ${ }^{27}$. Sin duda alguna se habia producido un cambio radical.

Esta victoria, tras cuarenta años de inferioridad frente a los vecinos ilirios, y tras la grave derrota de 360, hará que Macedonia vea en Filipo a su salvador y líder, y que los falangitas, en opinión de Hammond, tomen conciencia de la superioridad de su armamento y sus tácticas ${ }^{28}$. Además, la Alta Macedonia es incorporada al reino de Filipo, aumentando así sus efectivos militares y creando una frontera segura frente a los belicosos ilirios.

Macedonia se va introduciendo poco a poco en los conflictos griegos, tras imponerse en el norte balcánico ${ }^{29}$. Respondiendo a las peticiones de ayuda de los aristoi de Larisa frente a Feras y los sucesores de Jasón, acude en su ayuda ya en los años 358 y $357^{30}$, si bien el momento de mayor importancia se da en 354, tras el estallido de la Tercera Guerra Sagrada el año

${ }_{26}$ Cinoscéfala: Plut. Pel 32.3.7; Mantinea: Jen. Hel. 7.5.22, D.S. 15.85.2-8. En mi opinión, la infantería de los flancos ilirios no estaba compuesta por hoplitas, sino únicamente cierta parte del ejército, que suponemos ocupaba el centro de la linea junto a Bardilis.

27 Sobre la infanteria macedónica tradicional, op. cit. c.3. Sobre la derrota de Pérdicas en 360 , D.S. 16.2.4-6, Polieno 4.10.1.

${ }^{28}$ N. G. L. Hammond (1994), «Macedonia before Philip and Philip's first year in power», MedArch 7, 15

29 En 356 Atenas reúne a los enemigos de Macedonia para hacer frente a su incipiente poder. Cetriporo de Tracia, Lipeo de Peonia, y Grabo de las tribus ilirias meridionales firman una alianza militar frente a Macedonia. Sin embargo, Atenas tiene que hacer frente a las revueltas de sus aliados, mientras ilirios y peonios quedan inmovilizados por el nuevo sistema de defensa macedonio que no permite la comunicación entre ambos, dadas las características geográficas y el control de un pequeño número de pasos montañosos, que aseguraban la defensa de las fronteras del reino (véase H.J. Dell, “Philip and Macedorian Northern neighbours", en Hatzopoulos y Loukopoulos (eds.) Philip of Macedon, Atenas 1980, 90-99; Hammond, "The kingdoms of Illyria circa 400-167 B.C.", BSA 61, 1967, 239-251). Filipo toma la iniciativa y conduce a su ejército contra Cetriporo y Lipeo, los cuales se retiran antes de dar batalla. Inmediatamente Filipo vuelve a sus tropas contra Grabo, que fue derrotado por Parmenión "en una gran batalla" (D.S. 16.22.3; también aparece en Justino 12.16.6, y Plut. Ale., 3.5; las diferentes victorias de Filipo en lliria son mencionadas también en Demóstenes, Primera Filípica 48, y Primera Olintíaca 13, y en Isócrates, Filipo 21). Por desgracia, las fuentes únicamente se limitan a mencionar el enfrentamiento, que concluyó con victoria macedónica, de la que Hammond opina que fue obra de la falange (Hammond, Philip of Macedon, Londres 1994, 111: "another victory no doubt for the pikemen-phalanx").

${ }^{30}$ De la primera intervención del 358 únicamente sabemos que Filipo dirigió una campaña junto a Larisa, seguramente contra Feras, gracias a un fragmento de la Filipica de Teopompo (F34); de la segunda, en 357/6, Diodoro 16.14.1-2, nos cuenta que Filipo penetró en Tesalia en ayuda de sus aliados de Larisa 
anterior. Filipo desciende a Tesalia con su ejército para enfrentarse a Licofronte, que llama inmediatamente a sus aliados focidios; tras la llegada de Failo, que había sido enviado por Onomarco con parte de su ejército mercenario (siete mil hombres), Filipo obtiene la primera victoria frente a ambos aliados en el verano de ese mismo año, si bien no tenemos más datos sobre este enfrentamiento ${ }^{31}$. A finales de verano de ese mismo año, Onomarco acude en ayuda de su aliada Feras con un gran ejército mercenario compuesto de veinte mil infantes, quinientos jinetes y cierto número de armas de asedio $^{32}$. Onomarco era superior en número a Filipo, pero la diferencia no pudo ser demasiado grande ya que parece que ambos generales esperaban obtener una victoria decisiva en este enfrentamiento. Filipo será derrotado en dos ocasiones durante esta campaña y hubo de retirarse. Del primer enfrentamiento no sabemos nada, si bien el hecho de que se llegara a un segundo nos induce a pensar que el resultado no fue decisivo. En cuanto a este segundo, contamos con el siguiente fragmento de Polieno:

«Eligiendo una posición frente a una montaña con forma de media luna, y escondiendo sus catapultas con su munición de piedras y sus artilleros en la zona alta de cada flanco, (Onomarco) dirigió a su ejército hacia el terreno llano. Cuando los macedonios les salieron al encuentro y les disparaban de lejos, los focidios fingieron huir hacia la zona central de la montaña. Los macedonios cargaron con ánimo e ímpetu, pero la falange macedónica fue lanzada al desorden por el fuego de las catapultas desde terreno superior. Entonces Onomarco mandó a sus focidios girarse y cargar contra el enemigo. Cogidos entre el fuego de la artillería y la carga desde un terreno más elevado, las tropas macedónicas se retiraron con grandes dificultades y pérdidas en su huida" ${ }^{33}$.

No conocemos ni el nombre ni la localización de esta segunda victoria, pero sí ciertos datos decisivos: en primer lugar, Onomarco finge una postura defensiva para atraer el ataque macedonio, que pudo verse condicionada no sólo por la encerrona del focidio, sino también por la dificultad de desplegar un ataque directo contra la falange macedónica, que con sus sarisas sobrepasaba el alcance de las lanzas hoplíticas; esto, junto a la superioridad de su caballería, le daba nuevamente a Filipo la iniciativa del combate ${ }^{34}$. Onomarco elige para el combate una posición llana con una elevación a su es-

y derrota a los tiranos de Feras; Justino 7.6.6-9, indica que Filipo capturó Larisa y se hace con Tesalia. Los historiadores creen que tanto Diodoro como Justino se refieren al periodo posterior a la batalla de los Campos de Azafrán: M. Sordi, La Lega Tessala, Roma 1952, 349; Griffith, HM II, 224-30; T.R. Martin, “A phantom fragmento of Theopompus...". HSCP 86 (1982), 72-73.

31 D.S. 16.33 .4

32 D.S. $16.35 .1-2$

33 Polieno 2.38.2; también menciona Diodoro este enfrentamiento en 16.35.2-3, pero si aportar apenas datos, como ocurre en el resto de los casos.

34 Contra la opinión de Markle (1978), 487, que sostiene que la falange macedónica tampoco tomó parte en este enfrentamiento, ya que si hubiera sido asi las bajas del ejército macedonio habrian sido mayores; asimismo dice que las únicas armas que se supone aparecen en el texto serian las jabalinas,

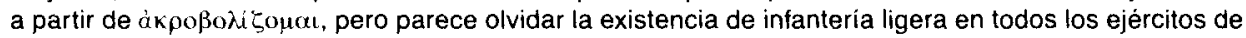


palda con forma de media luna, en la que oculta su artillería ${ }^{35}$. Toma posición en el llano y comienza el enfrentamiento: tras el hostigamiento inicial de los macedonios (por medio de la infantería ligera), la falange hoplítica de los mercenarios se retira seguida por los macedonios, hasta que éstos se encontraron a tiro de los lanzadores de piedras enemigos, tras lo cual la falange de Onomarco volvió a girar, cargando contra los macedonios. Sólo con gran dificultad pudo Filipo sacar a su ejército de tal encerrona, y con buen número de bajas. La victoria de Onomarco se debe sobre todo al uso de máquinas de asedio y a la astucia de éste, gracias a la cual Filipo y su ejército se vieron superados; en ningún caso podemos decir que el ejército mercenario focidio fuera superior al macedonio. El monarca macedonio consiguió devolver el orden a sus filas, ayudadas en la retirada por la caballería, previniendo la derrota total en caso de haber huido sin orden.

A finales de la primavera del año siguiente, el macedonio regresa a Tesalia con su ejército al completo ${ }^{36}$, que junto a sus aliados tesalios sumaría veinte mil infantes y tres mil jinetes, y pone sitio al puerto de Feras, Pagasas ${ }^{37}$. Onomarco, al mando de quinientos jinetes y veinte mil soldados (la mayoría hoplitas mercenarios experimentados), acude rápidamente en su ayuda, en dirección a Pagasas para encontrarse con la armada ateniense que había acudido en su apoyo, y una vez reunidos enfrentarse junto a sus aliados de Feras contra el ejército de Filipo y la Confederación Tesalia. Sin embargo, parece que Onomarco se dirigió al Norte desde Beocia sin preocuparse por protegerse de un posible ataque macedonio, y no tomó ninguna de las rutas montañosas alternativas que le habrian proporcionado una mayor protección, asi como un terreno en parte más apropiado, como veremos ${ }^{38}$. Filipo, consciente de su momentánea superioridad, corre a su encuentro en dirección sur

la época, que abrían el ataque y hostigaban inicialmente al ejército enemigo, tropas que en este momen-

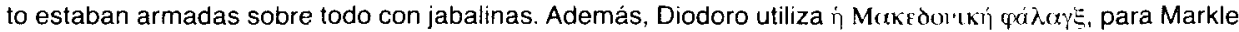
la falange hoplítica de los macedonios, pero de lo que parece más adecuada la lectura falange macedónica (armada con sarisas), por las razones que aducíamos antes.

${ }_{35}$ Para un análisis de la maquinaria de asedio de este periodo, véase E.W. Marsden, Greek and Roman Artillery: Historical Development, Oxford 1969, 59 y 164-68. Como señala acertadamente Griffith, HM 11, 270, las máquinas traídas por Onomarco tenian como objetivo el asedio de ciertas ciudades tesálicas, y en ningún caso su uso contra los macedonios en una batalla abierta, ya que estas máquinas no podían ser ensambladas y preparadas para la acción con velocidad, ni podian apartarse o huir ante el enemigo; de hecho, sólo oímos de su efectividad en ciertos casos en que los generales hacian un uso improvisado de las mismas, aprovechando las circunstancias y el elemento sorpresa, como es el caso.

36 De aproximadamente quince mil soldados, de acuerdo con Griffith HM II, 273, y J. Buckler (1989), Philip II and The Sacred War, Leiden, 74

37 Lo cual es deducido por Buckler (1989), 74, a partir de Demóstenes 1.9, 12, 4.35, y D.S. 16.31.6.

38 D.S. 16.35.4, 6. Onomarco seguramente sabía de la superioridad de Filipo en cuanto a la caballería, por to que resulta extraño que librara combate con Filipo antes de encontrarse con sus aliados. Quizá Onomarco subestimara a las tropas macedónicas, o simplemente se viera forzado por la situación (Buckler (1989), 75). En cualquier caso, hemos de tener en cuenta que su ejército ya había vencido al macedonio en dos ocasiones durante el año anterior, al igual que lo hicieran tebanos y atenienses en la década de 360 , por lo que quizá considerase a la falange de los hoplitas superior al ejército macedonio (no así la caballería). 
anticipándose a su encuentro con Licofronte y con la armada ateniense. El ejército de Filipo estaba compuesto por una potente caballería ${ }^{39}$, de la que aproximadamente la mitad debía ser macedónica. Sin duda Filipo tenía un objetivo claro: celebrar la batalla en terreno apropiado para ella. Tesalia disponía de amplias llanuras, y en ellas la caballería debía jugar un papel decisivo. Entre su infantería contaría con cierto número de infantería ligera, algunos hoplitas y sobre todo sus macedonios, seguramente organizados en la falange macedónica. Frente a ellos estaba la masa de mercenarios de Onomarco, en su mayoría hoplitas, pero suponemos que contaría con cuerpos de infantería ligera y peltastas, además de sus quinientos jinetes. Este enfrentamiento es conocido como la batalla del Campo de Azafrán.

Tal y como sugirió por primera vez Beloch, la localización del choque debió producirse en la llanura costera de Acaya Ftiotide, la única con espacio suficiente para el despliegue de más de cuarenta mil hombres y cercana a la costa, que además se encuentra en el camino que debía cruzar Onomarco para encontrarse con sus aliados ${ }^{40}$; no obstante, no sabemos en que zona concreta se produjo la batalla por lo que una reconstrucción exacta de ésta resulta imposible. En cualquier caso, una llanura de estas características es especialmente adecuada para la caballería, de la que Onomarco apenas disponia. Griffith ha sugerido que el flanco derecho pudo estar guardado por la línea de $\operatorname{costa}^{41}$, si bien Buckler lo descarta ya que Estrabón comenta que la llanura del Azafrán estaba un tanto al interior, y Diodoro y Pausanias dicen que Onomarco huyó a la costa, por lo cual no estaba en ella (máxime si tenemos en cuenta que la posición natural del general de un ejército hoplítico estaba precisamente en el flanco derecho), aunque sí estaría relativamente cerca ${ }^{42}$. Suponemos que Onomarco, consciente de la situación, buscaría algún accidente del terreno que guardara al menos uno de sus flancos, o quizá formó en cuadro, como hiciera Bardilis cinco años atrás. Sin embargo, la superioridad de la caballería macedónica y tesálica era aplastante, y el hecho de que se impusiera sobre la mercenaria enemiga era sólo cuestión de tiempo. Hecho esto, Onomarco estaría claramente a la defensiva y a merced de Filipo, quien utilizaría nuevamente a su infantería en conjunción con la caballería para abrir las líneas enemigas y cargar velozmente alli donde surgieran huecos o quedara al descubierto algún flanco. La victoria fue absoluta, y los mercenarios sufrieron hasta seis mil bajas, mientras otros tres mil eran capturados ${ }^{43}$. Diodoro atribuye la victoria

${ }^{39}$ La cifra de tres mil jinetes resulta excepcional para este periodo, en especial si tenemos en cuenta el alto nivel de la misma. Dicha cantidad posiblemente sea la respuesta de Filipo a las derrotas del año anterior. Parece anticiparse a las circunstancias y a la batalla, como señala Griffith HM II, 273. Su papel en la batalla, como quedaria demostrado, había de ser decisivo en un terreno apropiado.

${ }^{40}$ K.J. Beloch GG III2. 1.477 n.1.

41 Griffith HM II, 274.

42 Buckler (1989), 75; Estrabón 9.5.14; Pausanias 10.2.5; D.S. 16.35.5-6

43 Polieno 4.2 .20 ; D.S. 16.35.4. La cantidad de bajas y prisioneros, casi la mitad del ejército, resulta asombrosa si tenemos en cuenta otros enfrentamientos de la época (op. cit. n. 20). No obstante, resulta del todo lógica si tenemos en cuenta primero las férreas persecuciones caracteristicas de Filipo y Alejandro; segundo, las caracteristicas de un terreno especialmente adecuado para la caballeria, todo lo contrario 
a la caballería tesálica ${ }^{44}$ y no sin cierta razón ya que el enfrentamiento se produjo en una llanura donde tanto la caballería tesálica como la macedónica podian desplegarse y actuar sin obstáculos; sin embargo, resulta extraño que si Filipo tenía en mente una batalla de caballería, no hubiera traído consigo al menos un millar de sus Compañeros. Suponemos además que presionó a sus aliados tesalios para que aportaran hasta el último jinete disponible ${ }^{45}$. Pero debemos hacer una correcta valoración de los hechos y conceder también su importancia a la infantería macedónica de la falange, que empujaría a los hoplitas de Onomarco abriendo su formación o simplemente poniendo al descubierto algún flanco, por lo que el golpe de la caballería, asestado en los flancos y en los huecos surgidos resultaría mortal.

Pese a la diversidad de campañas de que tenemos constancia en el periodo siguiente, no volvemos a tener información sobre ninguna de las grandes batallas de Filipo hasta el gran enfrentamiento de Queronea ${ }^{46}$. La Confederación Anfictiónica declaró la guerra a Anfisa en 339 y nombró $\grave{\eta} \gamma \varepsilon \mu \omega v$ de sus fuerzas a Filipo. Atenas, entretanto, reunió una coalición de estados griegos para resistir la invasión macedónica de Grecia Central. En 338 , Filipo no espera la llegada de los meses hábiles para la guerra y se anticipa a los movimientos enemigos presentándose en Elatea tras atravesar Dóride con rapidez, utilizando el factor sorpresa y la velocidad de su experimentado ejército. Filipo pide paso a la Confederación beocia para marchar contra Atenas, pero los beocios deciden apoyar a ésta y envían un ejército mercenario para bloquear el paso de Gravia (que conducían a Anfisa), mientras otro ciudadano es enviado al de Parapótamos (que conducía a Beocia). Filipo, aprovechando la noche, toma por sorpresa el paso defendido por los mercenarios, derrotándolos y ocupando a su vez Anfisa ${ }^{47}$. Los aliados deciden retirarse y concentrar sus fuerzas en la llanura de Queronea, punto fuerte y bien defendido en el norte de Beocia.

para los hoplitas que huyeran (sin refugio y a merced de la veloz caballeria); y tercero, las posibilidades de huida se veian limitadas en uno de los lados por el mar, donde se ahogaron muchos de ios que intentaron nadar hasta la flota de Cares que pasaba por alli en aquel preciso momento (D.S. 16.35.5-6).

44 D.S. 16.35.4-5.

${ }_{45}$ Griffith HM II, 275, ha sugerido que quizás la fuente de Diodoro para esta batalla no apreciara demasiado a los macedonios, por lo que quizá sea ésa la causa de que conceda todo el mérito de la batalla a los tesalios.

46 Vemos de nuevo en acción al ejército macedonio durante las campañas contra la Confederación Calcídica y la destrucción de Olinto de $349-48$, en la que de acuerdo con D.S. 16.53.2, Filipo libró dos grandes batallas contra las fuerzas olintias antes de confinarlos a la ciudad, pero no dice nada más. Sin duda Filipo utilizó su caballería y su infantería frente a la poderosa caballería olintia y el alto número de hoplitas de que disponia la polis griega (Dem. 19.266), lo que unido a sus numerosos aliados (Philoc. FRG 328 F4951 y Dem. 19.266, 21.197), suponemos que obligarian a Filipo a emplearse al máximo y a concentrar a todo su ejército. Posteriormente vemos al ejército macedonio, entre otros, en la marcha sobre las Termópilas y la definitiva rendición de Fócide (346), las campañas contra lliria y Tracia (344 y 42-41, respectivamente), los sitios de Perinto y Bizancio (340), una nueva campaña contra Tracia (339), y finalmente la campaña contra Anfisa (339) que culminará en el gran enfrentamiento de Queronea (338).

47 Esquines 3.146; Polieno 4.2.8; Frontino 1.4.13; nuevamente carecemos de los detalles del enfrentamiento. 
En la batalla de Queronea del 338, Beocia y Atenas, junto a sus aliados Corinto, la Confederación Aquea, Mégara, Acarnania y Eubea, se enfrentan al ejército macedonio y a sus aliados de Grecia Central y Tesalia, entre otros. Es la contienda de que más información disponemos durante el reinado de Filipo, pese a no ser demasiado numerosa: Diodoro cuenta que el ejército de Filipo era superior en números y capacidad táctica, que Alejandro dirigió el ataque decisivo y que Filipo contribuyó notablemente a su victoria ${ }^{48}$. Justino, por el contrario, dice que el ejército griego era muy superior en número, y el macedonio en calidad ${ }^{49}$. Plutarco añade algunos detalles sobre Alejandro y el BataIlón Sagrado, y nombra varias características de la zona, hoy incontrastables ${ }^{50}$. Pausanias habla del León de Queronea y los muertos que conmemora ${ }^{51}$. Y Polieno narra la táctica seguida por Filipo y que le permitió vencer la batalla, aunque ofrece varias dificultades que veremos ${ }^{52}$. Por su parte, la arqueología ha descubierto dos túmulos, uno en cada extremo de la batalla: el túmulo funerario en el extremo norte ha sido identificado como el $\Pi \circ \lambda a^{\prime} \delta \rho\llcorner o v$ de los macedonios que fueron incinerados en una gran pila funeraria; se acepta que ésta es el área donde se desplegaron los macedonios, concretamente en el ala de Alejandro, y donde sufrieron más bajas (suponemos que frente al Batallón Sagrado especialmente) ${ }^{53}$. En opinión de Griffith, es muy probable que señale el lugar en que se desplegó el ala derecha griega, que habría sido el flanco que más resistió protegido en uno de sus lados por el Cefiso, y donde el Batallón Sagrado aguantó hasta el final ${ }^{54}$. El punto opuesto del campo de batalla está marcado por el León de Queronea, del que Pausanias dice que se encuentra sobre la fosa común de los tebanos ${ }^{55}$. Pero este monumento no tenía ninguna inscripción cuando lo vio Pausanias, y un buen número de historiadores dudó de su veracidad. Sin embargo las excavaciones de P. Stamatakes en 1880 lo apoya más que lo descarta: descubrió otro Пlo$\lambda \iota$ ávopıov con doscientos cincuenta y cuatro esqueletos colocados en hileras, no cremados - como hacían los macedonios - y su número recuerda mucho al de trescientos del Batallón Sagrado (además, hemos de suponer que aunque las fuentes digan que cayeron todos en su posición, es probable que no todos murieran allí mismo); sin embargo, aparecen en el lado opuesto del campo de batalla, muy lejos del lugar en que cayeron ${ }^{56}$.

48 D.S. 16.85 .5 ff. y 86 .

49 Justino 9.3

50 Plut. Pelop. 18.7, 23.2, y Ale. 9.2.

51 Pausanias 9.40 .10 .

52 Polieno Strat. 4..2.2 y 7

53 G. Sotiriades MDAl (A) 28 (1903) 301-30; "Das Schlachtfeld von Chäeronea”, MDAl (A) 30 (1905) 11320; Cf. Plu. Ale. 9.3, y Pel. 18.7. P.A. Rahe, "The Annihilation of the Sacred Band", AJA 1985, 1981, 84-87

54 Griffith HM II, 598; Rahe, "Annihilation...", 86.

55 Pausanias 9.40.10; cf. Strab. 9.2.37 (414).

56 En opinión de Griffith HM II, 598 c.7, los macedonios habrian sido enterrados antes, mientras que en el lado opuesto de la batalla se erigió el León de Queronea para que estuvieran separados; además, pone cierto énfasis en la mayor afinidad de la aristocracia y la oligarquía de Tebas con Filipo, que el resto de los tebanos; y los falangitas del Batallón Sagrado pertenecian al primer grupo, por lo que es posible que las clases altas llegaran a un acuerdo con Filipo para hacer honores al Batallón. Por el contrario Hammond, 
La localización y disposición de los ejércitos no aparece de forma explícita en las fuentes, por lo que debemos guiarnos por suposiciones y análisis geográficos de la zona en la actualidad. Hammond, apoyado posteriormente por Pritchett, identificó el riachuelo del Hemo que se cita en las fuentes, lo que nos permite asegurar en buena parte la posición de los griegos ${ }^{57}$. Plutarco dice de este río que incluso durante el verano bajaba lleno, y que durante la batalla estaba repleto de sangre y cuerpos, por lo que debió tratarse de un caudal a tener en cuenta ${ }^{58}$. El ala derecha griega, cerca del túmulo macedonio y del Cefiso, no está en absoluto cerca del Hemo ni de ningún otro afluente que cruzara la llanura, por lo que sólo el ala izquierda griega de los atenienses pudo estar cerca del Hemo (de acuerdo con las fuentes), concretamente en el lugar en el que entra en la llanura. Si los atenienses ocuparon el flanco izquierdo junto a la ciudad y las estribaciones montañosas, es seguro que tebanos y beocios lo hicieron en el flanco derecho junto al río, y los aliados en el centro de la línea. Asimismo los griegos ocupaban una posición ventajosa y que además les permitia una huida fácil ${ }^{59}$.

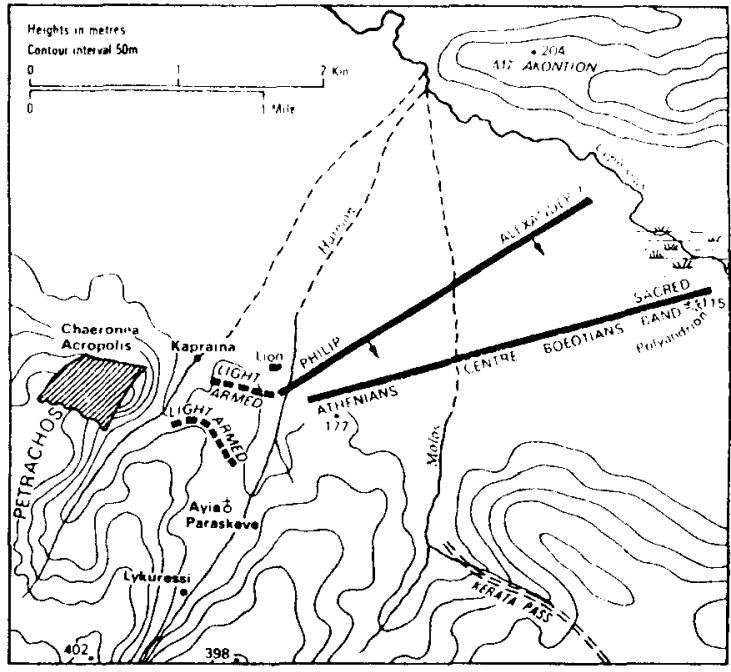

*Mapa de Queronea: en N.G.L. Hammond y G.T. Griffith, A History of Macedonia, vol. II, Oxford 1979, 596.

Studies in Greek History, (versión revisada de "The two bateles of Chaeronea") Oxford 1973, 554 f., sostiene que las malas relaciones de Filipo y Tebas, maltratada por el macedonio tras la batalla y en el tratado de paz, y posteriormente destruida por su hijo Alejandro, difícilmente habría obtenido el permiso para erigir un monumento a los caidos en lucha con Macedonia. Pritchett, "Observations on Chaeronea", AJA 62, 1958, 311 , sostiene una opinión más cercana a Griffith.

57 Hammond (1973), 540ff.; Pritchett (1958), 309; Griffith HM II, 599; Markle (1978), 488.

58 Plut. Dem. 19.

59 Por el paso de Kerata a Beocia Central, opuesto al lago Copais; parece que los atenienses huyeron por esta ruta: Plut. Mor. 849 A. Hammond (1973), 539. 
Filipo posiblemente fuera inferior en número, pero no por mucho. De acuerdo con Diodoro, los macedonios presentan en el campo de batalla treinta mil infantes y dos mil jinetes, pero de los griegos no dice nada ${ }^{60}$. Kromayer ha supuesto un número similar de caballería en el bando defensor, o quizá ligeramente menor, pero en cualquier caso los griegos sabían que la caballería macedónica y tesalia era superior ${ }^{61}$. Plutarco habla de dos mil jinetes mercenarios griegos, pero parece una cifra dudosa ${ }^{62}$. Kromayer nuevamente estimó que la infantería griega estaría compuesta por treinta y cinco mil soldados, una cifra que parece razonable; de ellos, cerca de veinticinco mil debieron ser hoplitas, quizá treinta mil, y entre atenienses y beocios pudieron suponer dos tercios del total. En el bando macedonio, veinte de los treinta mil infantes debieron ser macedonios $^{63}$. Los aliados griegos se desplegaron entre la ciudad y el río Cefiso, en una línea de unos tres kilómetros y suponemos que con ocho escudos de profundidad, no dejando espacios más allá de los flancos para impedir el despliegue de la caballería ${ }^{64}$. Además, el Cefiso formaba un ángulo sobre el que las tropas griegas podrían pivotar y envolver a los macedonios. La elección griega es perfectamente lógica, y les daba una oportunidad clara de imponerse a Filipo. Cabe notar que pese a la derrota de Onomarco y el resto de las victorias macedónicas (en las que suponemos que la falange jugaría un papel destacado), los hoplitas griegos apenas habian modificado ni sus tácticas ni su equipo. Sin embargo, como recuerda Hammond, los hoplitas ya habían vencido una vez a las tropas macedónicas en 354, y las fuerzas beocias eran consideradas las mejores de Grecia, por lo que los griegos todavia confiaban en sus posibilidades y su panoplia tradicional ${ }^{65}$.

Filipo, por su parte, ve que el territorio le ofrece también amplias posibilidades de victoria: si tenemos en cuenta la geografía griega y las circunstancias en que se había visto anteriormente el macedonio, bloqueado en las Termópilas, la llanura de Queronea es bastante amplia y apta para el despliegue de la falange macedónica y la caballería. Las irregularidades del terreno protegían a priori los flancos de la falange griega, pero si planteaba una batalla con cierta movilidad, las líneas enemigas podrían ponerse al descubierto y abrir algunos huecos que serían explotados sobre todo por la caballería ${ }^{66}$. Además, Filipo sabía que su ejército, a pesar de encontrarse en aparente inferioridad numérica,

60 D.S. 16.85 .5

61 J. Kromarer y G. Veith (eds.), Antique Schlachtfelder in Griechenland, Berlin 1903-31, 1.195.

62 Plut. Dem. 17.3

63 Cifras de Griffith HM 2, 600

64 Hammond (1994), Philip... 152. Dicho despliegue negaba también el despliegue y uso de su propia caballeria, ya que sin duda los griegos eran conscientes de su inferioridad cualitativa. Quizá fuera desplegada en retaguardia, como protección ante una hipotética retirada o huída, o quizá como reserva para hacer frente a cualquier situación que lo requiriera. Por otro lado las fuentes no mencionan a la caballeria tesalia, pero es muy probable que tomara parte en la batalla.

${ }_{65}$ HAMMOND (1994), Philip... 116: «as Onomarchus had shown, the mercenaries rivalled the Macedonian pikemen in quality, and the Boeotian hoplites were the finest in Greece and had much better experience".

66 Frente a la opinión de Rahe, “Annihilation...", 87, de que la caballería no jugó un papel importante en la batalla, ya que ninguna fuente habla de rotura en las lineas griegas. Interpretación en mi opinión errónea, como veremos posteriormente. 
era superior en cuanto a entrenamiento, experiencia y armamento se refiere. $\mathrm{EI}$ problema que se planteaba era el de cómo desplegar a la falange de modo que pudiera enfrentarse al enemigo sin ser flanqueada, cómo sobreponerse a la superior posición del enemigo, y cómo abrir las filas enemigas para aprovechar el potencial de la cabaliería. En cuanto al orden de batalla, sólo sabemos que el propio Filipo se sitúa al frente de su infantería en el flanco derecho, frente al izquierdo de los atenienses, y que Alejandro ocupa el flanco izquierdo frente a tebanos y beocios ${ }^{67}$.

El papel de la caballería, como había ocurrido en los anteriores enfrentamientos, debía ser una de las claves. En opinión de Griffith, estas claves de la batalla habrían sido especialmente el cómo fue roto o inducido a ofrecer algún hueco el muro de hoplitas griego, y cómo la caballería penetró por él destruyendo la línea enemiga ${ }^{68}$. No obstante, no debemos perder de vista a la falange macedónica, superior por sí sola a la enemiga, y que jugaría un papel básico en colaboración con la caballería. La respuesta a estas preguntas las podemos obtener en las fuentes, si bien no aparecen demasiado claras: en Plutarco leemos "se dice que (Alejandro) fue el primero en atacar al Batallón Sagrado tebano" 69 . Diodoro dice algo muy parecido, y coloca el triunfo de Filipo en el ala opuesta poco después ${ }^{70}$. En Polieno, Filipo llevó a cabo una retirada controlada hasta el punto en que pudo contraatacar ${ }^{71}$. Veamos primero el flanco izquierdo, en el que se sitúa Alejandro: desde luego el asalto al Batallón Sagrado no pudo ocurrir al principio de la batalla, ya que los tebanos no podían ser flanqueados, y las posibilidades de una carga directa de la caballería contra las filas ordenadas de la falange hoplítica parece demasiado arriesgado (máxime contra la mejor unidad del ejército enemigo) ${ }^{72}$. Habría que atacar antes de otro modo, por medio de la infantería macedónica, que presionaría duramente sobre la formación enemiga, en la que pudieron surgir huecos, contra los que sería más fácil y seguro dirigir el ataque directo de la caballería, más demoledor. Sólo en el caso de que las filas enemigas hubieran permitido la aparición de la caballería, ésta podría haber cruzado las filas griegas y cargado contra el Batallón Sagrado tebano, pero en un momento posterior en cualquier caso. Seguramente Plutarco trataba de exaltar la figura de Pelópidas (objeto de su biografía) mientras Diodoro resulta demasiado teatral y poco metódico.

La maniobra que narra Polieno en el flanco opuesto resulta más sugestiva. La primera de las dos estratagemas de Filipo en esta batalla es la siguierite: «En Queronea, Filipo era conocedor de la temeridad y falta de preparación de los atenienses, en tanto que los macedonios estaban preparados y ejercitados, por lo que prolongando las líneas de su falange, los sobrepasó y los tuvo a su

67 Polieno 4.2.2 y 7, sobre Filipo; Plut. Ale. 9.3, sobre Alejandro.

68 Griffith HM II, 600.

69 Plu. Ale. 9.3.

70 D.S. $16.86 .3-4$

71 Polieno 4.2 .2 y 7

72 Rahe, “Annihilation...", 87; Op. cit. n. 10. 
merced $>73$. Al ver Filipo que los atenienses eran inferiores a sus macedonios,

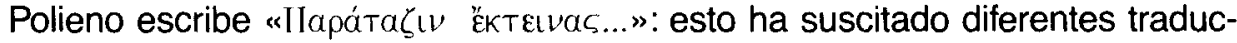
ciones, que varían mucho el significado del texto: para Kromayer y Griffith, IJa-

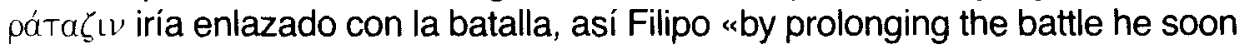
exhausted the Athenians " $^{74}$. No obstante Frontino, que sigue la misma fuente que Polieno, entiende "alargar el espacio", más que el tiempo de la batalla; $y$ Hammond, ciñéndose al aspecto militar de Ilapà líneas de la falange, por lo que Filipo "extended his formation a lot, and quickly loosened the Athenians (i.e. their formation) and made them easy to defeat $>75$. Markle, por su parte, opina que Polieno se refiere a la extensión de la línea macedónica; sin embargo, para este autor esto entraría en contradicción con el siguiente fragmento de Polieno cuando dice que Filipo mantuvo su falange en un orden más cerrado que el de los atenienses, lo que en parte le permitió imponerse a éstos ${ }^{76} ; \sin$ embargo Markle no tiene en cuenta que Polieno bien podría estar refiriéndose a otra fase de la batalla, como creemos que así fue ${ }^{77}$. Cualquiera que sea la traducción (perdieran la posición los atenienses, abrieran sus filas o quedaran exhaustos), parece que los atenienses fueron incapaces de aguantar la carga de los más selectos macedonios.

La segunda estratagema de que nos habla Polieno resulta decisiva: "Cuando Filipo se enfrentaba a los atenienses, abandonando la lucha se retiró. Estatocles, el estratego ateniense, lo perseguía... (Filipo) retrocedía lentamente con la falange replegada y protegida por sus armas. Cuando al poco tiempo se hubo retirado a una zona elevada, animando a sus soldados se dio media vuelta, cargó contra los atenienses valientemente, y luchando de forma excepcional los venció ${ }^{78}$. Si confiamos en la verosimilitud de este fragmento, llegamos a la conclusión de que la actuación de Filipo formaba parte de un plan preconcebido, ya que una maniobra de estas características era sin duda arriesgada, y su objetivo sólo podía ser el de desplazar el combate a una zona más adecuada para sus tropas, así como hacer que las líneas enemigas perdieran tanto su posición como su unidad

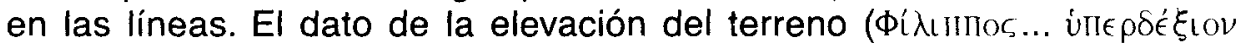

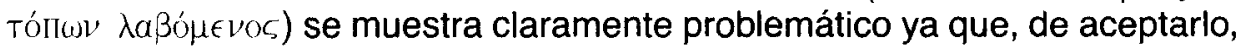

73 Polieno 4.2.7.

74 Griffith HM II, 601; Kromayer, Antique Schlachtfelder... 168, n. 3.

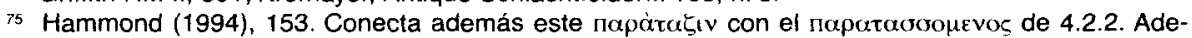

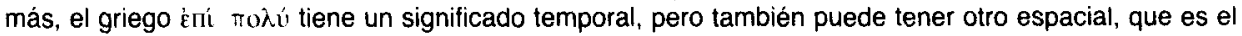
que le da Hammond aqui (véase LSj s.v. no $\lambda$ uc III 4 ab), frente a Griffith, 601, y Frontino 2.1.9. La traducción de Il $\alpha \dot{\varepsilon} \lambda v_{\sigma \varepsilon}$ ha suscitado ciertas dudas, sin embargo $\lambda \dot{v} \omega$ significa en este contexto perder la formación de la falange, sin duda. Hammond (1980), 61, opina que Polieno se refiere a la apertura o la pérdida de la formación de la línea ateniense a medida que la falange macedónica avanzaba impetuosamente; por el contrario, Griffith HM II, 601, da una interpretación temporal, como hemos visto, tomando como punto fuerte $\dot{\varepsilon}$ ni $\pi 0 \lambda \dot{v}$ y la traducción de Frontino 2.1 .9 , frente a Hammond que subraya $\mu \varepsilon \tau \dot{\tau} \delta \lambda_{i} \gamma o v$ de 4.2 .2 y $\tau \alpha-$ $\zeta \dot{\xi} \omega 5$, y que propone que no hubo un verdadero enfrentamiento entre macedonios y atenienses hasta que Filipo atacó

${ }^{76}$ Markle (1978), 491.

77 Rahe, "Annihilation...", 87.

78 Polieno 4.2.2. 
estaríamos hablando de las colinas en la esquina sur de la llanura que es la única elevación lógica que podemos localizar en el campo de batalla: ello llevó a Kromayer a reconstruir la batalla de forma que Filipo retiraba su ala derecha a las colinas del Turión, al oeste del Hemo: esto habría resultado imposible tanto por la distancia como por la duración de la retirada de Filipo, ya que los atenienses presionaban su formación, y hubiera dividido su propio ejército ${ }^{79}$. Hammond, por el contrario, sostiene que Filipo se retiró sólo hasta el Hemo, cuya orilla elevada pudo ser el «terreno elevado» del texto: la distancia propuesta es de aproximadamente ciento cincuenta metros, y Hammond a estimado que la duración hubiera sido de una media hora, algo relativamente factible ${ }^{80}$. Markle, alejándose un tanto de la traducción estricta, interpreta esto como "terreno ventajoso": Filipo saca a los atenienses de su posición elevada y gana una posición más favorable ${ }^{81}$. Pritchett, por su parte, muestra cierta renuencia a aceptar cada detalle al pie de la letra, y en este punto opina que este "terreno elevado" tiene seguramente cierta verosimilitud, sin ser una descripción exacta del terreno ${ }^{82}$. En cualquier caso, Hammond tiene razón al situar el Hemo como punto extremo y prácticamente insalvable, ya que la falange ateniense presionaba a los macedonios de cerca, y el paso de un obstáculo como este podría haber desecho las líneas macedónicas y abrir huecos en sus líneas, mortales para cualquier falange pero especialmente para la macedónica ${ }^{83}$.

Durante la batalla, creemos que Filipo realizó nuevamente un avance oblicuo dejando al resto de su ejército ligeramente retrasado, ya que avanza al frente del flanco derecho únicamente. Tras tomar contacto, se retira en orden. Mientras, es posible que el centro girara hacia delante hasta que toda la línea queda paralela a la griega, en una longitud aproximada de tres kilómetros. Una vez desplazada la línea ateniense y con ella toda la griega, que además pierde su posición elevada, volvió sus filas contra las atenienses. De esta forma conseguía su principal objetivo, que era hacer que la línea ateniense abandonara su posición elevada, y obligar al resto del

79 Kromayer, Antique Schlachtfelder... I.167.

80 Hammond (1974), 544ff; Griffith lo acepta como válido, HM II, 602.

81 Markle (1978), 497. Recordemos que Markle está pensando en una falange macedónica de tipo hoplitico, con la que una retirada de estas características habría sido más factible, en especial teniendo en cuenta las caracteristicas del terreno, que en este flanco era más accidentado. Asimismo considera posible esta retirada teniendo en cuenta que los falangitas de Filipo eran veteranos y disciplinados. No obstante, las estribaciones más complicadas quedan más a la derecha de Filipo, y su falange macedónica estaba bien entrenada, especialmente si consideramos que posiblemente utilizara para esta maniobra a sus hipaspistas, dadas las dificultades (pese a que las fuentes no dicen nada al respecto). Asimismo, y como veremos a continuación, resulta más dificultosa una retirada de estas características armados con lanzas hopliticas que con sarisas macedónicas, teniendo en cuenta que cada hoplita se enfrentaba a tres o cuatro sarisas antes de poder golpear a los macedonios; por ello mantener al enemigo a cierta distancia habría sido mucho más viable que entrentarse directamente a las lanzas, retirándose de espaldas, y con toda una línea de hoplitas presionando (por muchos escudos que tuvieran). Sin duda se habrian visto desbordados.

B2 Pritchett (1958), 310 c.3.

${ }_{83}$ Pese a que el riachuelo que ha sido identificado como el Hemo parece hoy de menor, sabemos que su caudal era entonces considerable: op. cit. n. 58 
ejército griego a moverse junto con ellos para no ofrecer huecos o flancos descubiertos. Esto provocó sin duda una extensión de las líneas y la apertura de huecos por los que penetraria su poderosa caballería ${ }^{84}$. Hemos de tener en cuenta que al alargar la posición (suponemos que en dirección noroeste), una línea estática de poco más de tres kilómetros como esta de los hoplitas griegos, o abría el flanco de su ala derecha, o simplemente se creaban huecos entre una y otra falange, ya que la línea seguramente se desplazó ligeramente a la izquierda, siguiendo a Filipo, y las condiciones geográficas eran irregulares; una y otra solución ofrecían un punto débil que Filipo podría aprovechar, sobre todo por medio de la caballería. Es posible que el Batallón Sagrado hubiera mantenido su posición, anclado en la rivera del río donde mantenía su flanco protegido frente a la caballería enemiga, provocando con ello un hueco en el ala derecha de la falange griega que, entonces sí, habría aprovechado la caballería de los Compañeros bajo el mando de Alejandro para introducirse y cargar contra la formación enemiga tebana que tenía frente a él ${ }^{85}$. De seguir esta interpretación, el ala izquierda macedónica habría explotado esta brecha y cortado la línea derecha griega entre los tebanos y el resto del ejército. En cualquier caso, no podemos saber dónde se dieron los primeros golpes de la caballería. Una vez conseguido este doble objetivo, Filipo se giró al mando de la falange del ala derecha y se enfrentó a los hoplitas atenienses, a los que desbordó al dilatar la batalla, o al aumentar la longitud de sus líneas y flanquear a los menos experimentados atenienses ${ }^{86}$. De acuerdo con el texto de Polieno, Filipo cedió terreno ante los atenienses, paso a paso, manteniendo la falange contraída y protegida en el interior de sus armas; armas que interpretamos como las propias de la falange macedónica, esto es, escudos ligeros, corseletes y sobre todo sarisas ${ }^{87}$, de manera que las líneas de hoplitas ateniense perseguirían de cerca a las macedónicas, a cuatro o cinco sarisas de distancia. Dentro de las dudas razonables que suscita este pasaje y la arriesgada maniobra de Filipo, únicamente podemos interpretar esta especie de persecución como la de una falange hoplitica a otra macedónica, ya que si ambas hubieran estado compuestas de hoplitas, los atenienses habrían cargado con todo su peso y empuje, sobrepasando a la macedónica

84 Hammond (1980), "Training in the use of sarissa and its effects in battle, 359-333 B.C.", Antichthon 14, 60, y (1994), 153-54; Griffith HM II, 602

85 Hammond, idem, sostiene que este hueco pudo surgir tambièn entre la infanteria tebana y la del resto de Beocia, ya que cada beotarco estaba al mando de sus propias tropas nacionales, y es posible que los tebanos eligieran mantener el contacto con su Batallón Sagrado. Seguramente las tropas aliadas del centro griego siguieran a las atenienses para no romper las filas, sobre todo en el punto donde se daba el enfrentamiento principal y que además podía darles la victoria.

86 A lo que Hammond (1980) 60, añade la disposición más compacta de la falange macedónica. En nuestra opinión, hemos de añadir el dato obvio de la superioridad macedónica tanto en la preparación de las tropas como en el armamento.

87 Existe cierto debate en torno a la traducción de ölıwov: Markle (1978), 488, lo ha interpretado como escudos del tipo aspis hoplitico, y en general las armas de la panoplia griega, que en orden cerrado permiten una gran protección. No obstante, la opinión generalizada es la contraria. Para una correcta valoración, op. cit. n. 81 
y derrotándola (es por ello que la retirada deliberada y prolongada a la distancia de una lanza normal nunca se intentó en la antigüedad, al menos que nosotros sepamos). Polieno concluye diciendo que Filipo, al entrar en terreno elevado, se giró contra los atenienses y los derrotó.

La caballería de Filipo, al igual que la de la mayoría de los ejércitos, se encontraba invariablemente en las alas; sin embargo, el terreno en el ala derecha era escarpado e inadecuado para la caballería, mientras que el Cefiso negaba su movilidad en el ala izquierda, y los griegos anclaron a lo mejor de su infantería junto a éste. Ello descarta también el ala izquierda como la posición de la caballería, al menos inicialmente ${ }^{88}$. No obstante, tenemos ciertas evidencias de que la participación de la caballería en Queronea ${ }^{89}$, y no creemos que Filipo dejara de utilizar a sus dos mil jinetes, que eran una de las mejores unidades de su ejército. En opinión de Griffith, ésta pudo ocupar la zona izquierda del centro, y en su extremo estarian situadas varias taxeis de la falange, con el objetivo de contener tanto como fuera posible a la peligrosa formación tebana, que probablemente adoptara de nuevo una formación más profunda que las restantes; en tales circunstancias, la infantería macedónica del ala izquierda pudo ceder terreno ante el empuje beocio, lo que habría supuesto el desplazamiento de sus filas respecto al resto del ejército griego y daría a la caballería la oportunidad de atacar el flanco interno beocio ${ }^{90}$. El flanco derecho griego es accidentado, y poco apto para el despliegue de la falange o la caballería, por lo que suponemos que fue explotado por la infantería ligera de ambos bandos ${ }^{91}$. Asimismo, resulta evidente que la retirada de Filipo en el flanco derecho fue protagonizada por la infantería de la falange macedónica. Por tanto, si su objetivo era abrir las filas enemigas para facilitar la carga de la caballería, al menos parte de ésta debió situarse en la retaguardia de la falange (ya que no podían saber en qué puntos surgirían los primeros huecos), y desde aquí desplazarse con celeridad a cualquier zona de la batalla por donde fuera posible su paso, en especial galopando a la izquierda de su falange (dejando el Cefiso a la izquierda), a medida que ésta avanzaba ${ }^{92}$. Markle, por su parte, propone una teoría algo más dudosa y radicalmente diferente: la carga directa de la caballería contra las filas tebanas desde el flanco izquierdo, dirigido por Alejan$\mathrm{dro}^{93}$. No obstante, esta hipótesis hace que la maniobra de Filipo en el ala derecha pierda parte de su sentido, y ello sin tener en cuenta que una

86 Contra Hammond (1994), 152

89 Sotiriades (1903), 308-9 y pl. 41, $n^{\circ} .1-4$ : habla de piezas mayores de hierro que quizás pertenecieran a la caballeria; asimismo recoge la presencia de unos anillos que podriamos identificar como bocados de caballos. Markle (1978), 289.

90 Griffith HM II, 602.

91 Hammond (1974), 543, fig. 23; Grffith HM II, 603.

92 Griffith sugiere que la retirada de Filipo pudo abrir un hueco en sus propias filas que habria aprovechado su caballería para pasar (HM II, 602).

93 Markle (1977), 337-39, y (1978), 491; ello además encajaria mejor con las fuentes que hablan de la carga de Alejandro en el ala izquierda macedónica: Plut. Ale. 9.2, y D.S. 16.86.3. 
carga de tales características en este momento no tendría precedentes (al menos en las fuentes), y habría sido bastante arriesgada si tenemos en cuenta que lo mejor de la infantería enemiga defendía esta zona, con el Batallón Sagrado al frente. Por el contrario Hammond y Rahe, ciñéndose a las fuentes ${ }^{94}$, han sugerido que Alejandro, al mando del flanco izquierdo, habría dirigido no a la caballería sino a la falange con sus sarisas en un ataque frontal contra los tebanos ${ }^{95}$. Nuevamente nos encontramos con la misma situación que se planteaba frente a la interpretación de Markle: el flanco ateniense es el más débil, y lanzarse contra la zona más fuerte y mejor protegida del enemigo resulta demasiado arriesgado; asimismo, este ataque haría que la estratagema de Filipo perdiera parte de su sentido, y si uno de los objetivos en la batalla era aprovechar la superioridad de la caballería (con la colaboración de la cual, no lo olvidemos, se habían vencido en las anteriores batallas), limitarse a intentar vencer la batalla por medio de la infanteria, punto fuerte del enemigo y objetivo de los aliados griegos, no encaja demasiado ni con las tácticas empleadas por Filipo, ni con el repliegue del macedonio en el ala opuesta, ni con las posibilidades de su ejército ${ }^{96}$.

Fuera como fuese, los golpes de la caballería en combinación con la falange fueron duros y efectivos, a juzgar por la alta cantidad de bajas enemigas de que nos hablan las fuentes: mil atenienses perdieron la vida y otros dos mil fueron capturados, mientras que entre los beocios cayeron «muchos», y otros tantos fueron capturados ${ }^{97}$. Pese a ello, parece que en esta ocasión Filipo no llevó a cabo una persecución tan sangrienta como en las anteriores, quizás por las dificultades del terreno, por la disponibilidad de vías de escape para los griegos ${ }^{98}$, o porque Filipo, como sugiere Hammond, ya estaba pensando en su posterior politica moderada ${ }^{99}$. Entre estos caídos de Queronea sabemos que se encontraba el Batallón Sagrado: tras la batalla, Plutarco cuenta lo siguiente: «Filipo encontró a todos (los miembros del batallón) yaciendo juntos con sus armas frente a las sarisas a las que hicieron frente ${ }^{100}$. Tenemos buenas razones para aceptarlo, ya que en el túmulo macedonio de Queronea (justo en la zona en que debió producirse el enfrentamiento con el Batallón Sagrado), se

94 Diodoro, en 16.86.3-4: “Alejandro fue el primero que en romper la sólida linea de la formación del

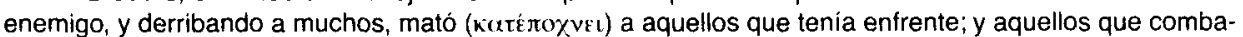
tían junto a él hicieron lo mismo y fueron abriendo huecos en la formación enemiga repetidamente", y poco después Filipo hizo lo mismo en el flanco derecho frente a los atenienses. Plutarco, Ale. 9.2: «Se dice que Alejandro fue el primero en atacar al Batallón Sagrado".

85 Hammond (1980), 63; Rahe, "Annihilation...", 87, sostiene que el vocabulario utilizado por Diodoro se corresponde con el de un choque de infanterías largo y duro.

*6 Algo diferente hubiera sido la combinación de caballería e infanteria, en cuyo caso sí aceptaríamos la opción propuesta. En cualquier caso, no podemos descartar del todo estas teorías.

97 D.S. 16.86.6; con los aqueos y aliados debió ocurrir lo mismo, a juzgar por el pasaje de Pausanias 7.6.5.

98 Op. cit. n.60.

99 Hammond (1973), 551, n.2.

100 Plut. Pel. 18.10. 
encontraron puntas de lanza superiores al tamaño normal, que bien pudieron ser de sarisas ${ }^{101}$. Es difícil saber si fue la caballería o la infantería la que lo hizo, ya que desde el punto geográfico este flanco es igualmente apto tanto para la caballería como para la falange macedónica, pero en nuestra opinión es muy probable que el golpe fuera asestado por ambas fuerzas de forma simultánea.

De acuerdo con algunos estudiosos, la batalla de Queronea muestra definitivamente la superioridad de la falange macedónica sobre la hoplítica. Desde luego, sabemos que los hoplitas fueron paulatinamente sustituidos por los falangitas macedonios en el siglo siguiente, lo que supone la prueba definitiva de la superioridad de unos sobre otros. Sin embargo, la victoria de Queronea lo que realmente demostró fue la superioridad definitiva del ejército de Filipo sobre los griegos, por la combinación de caballería e infantería, ambas de una calidad excelente, en los que las sarisas fueron sólo uno de los múltiples elementos con que contaba el macedonio ${ }^{102}$.

Resulta paradójico que las batallas que mejor ejemplificaron las tácticas de Filipo fueran aquellas que protagonizó su hijo Alejandro, hecho que debemos a la mayor cantidad de fuentes, evidentemente, pero también a las valiosas lecciones que recibió de su padre ${ }^{103}$. En Gránico, Isos, Gaugamela y otros enfrentamientos encontramos nuevamente el esquema establecido ya por Filipo, que se repite una y otra vez: la concentración de tropas en uno de los flancos, encargado de asestar un golpe demoledor sobre el enemigo, la disposición de las tropas en orden oblicuo, donde cada una de las armas tenía una función específica ${ }^{104}$, la sabia combinación de infantería pesada y

tot G. Sotiriades, “Das Schlachtfeld von Chäeronea”, AthMitt 28 (1903), 301-30. Quizá un nuevo estudio sobre los restos del túmulo macedonio podria ofrecer más pistas, en especial en lo referente a estas misteriosas puntas.

${ }_{102}$ Es cierto que ninguna formación de la época estaba en condiciones de cargar contra una falange armada con sarisas, lo cual concedia a Filipo y Alejandro la iniciativa del combate de forma invariable, algo que ambos supieron aprovechar. Asimismo la sarisa resulta un arma mortifera en el combate en falange. Sin embargo, estoy de acuerdo con las palabras de Pritchett, (1985), 45, cuando dice: "sarissas gave the advantage of the first strike in battle, (but) lacked the maneuveravility, and was only one element in battle".

103 Asi en Gránico será la caballeria al mando de Alejandro la que, seguida de cerca por los hipaspistas y junto a un pequeño grupo de ligeros, derrote a la caballeria enemiga en el flanco derecho, donde se había concentrado a lo mejor del ejército, mientras el resto de la falange avanzaba de forma inexorable nuevamente en orden oblicuo: D.S. 17.18.4-21.6; Arr. 13.1-16.2; Plut. Ale. 16.1; N.G.L. Hammond, "The Battle of the Granicus River», JHS 100, 1980, 73-88. En Isos serán los hipaspistas al mando de Alejandro los que asesten el golpe en el flanco derecho, seguidos de cerca por la caballeria, que aprovecha la situación y carga contra las brechas y los flancos enemigos: Arr. 2.8.1-12; Hammond, "alexander s charge in the Battle of issus in 333 B.C.", Historia 41, 1992, 395-406. En Gaugamela caballeria e infanteria crean un hueco en el ala derecha nuevamente, por el que penetra la caballeria de los Compañeros, Arr. 3.11.3-15.4.

104 La caballeria, junto a los hipaspistas, eran los encargados de asestar el golpe, en ocasiones directamente, en ocasiones junto a la actuación de la falange, cargando contra los flancos, la espaida o las brechas surgidas; ambos formaban la punta de lanza del ejército, mientras que los hipaspistas a su vez servían como bisagra respecto al resto de la falange, la cual avanzaria de forma imparabie con su muro de sarisas. La infantería ligera realizaba labores de apoyo. De acuerdo con Santosuosso (1997), 112: "The key of the Macedonian army would be the delicate balance between the different types of soldiers, and specially the fine complement of cavalry and heavy infantry". 
caballería ${ }^{105}$, el uso de las persecuciones como forma de asestar un golpe definitivo sobre el enemigo, o del elemento sorpresa y la velocidad de un ejército altamente preparado y capacitado para todo tipo de situaciones.

Tanto la falange macedónica como la caballería jugaron un papel decisivo en las victorias macedónicas, dentro de un ejército equilibrado, que combinaba los beneficios del soldado ciudadano y el profesional, y que bien dirigido no tenía rival. No en vano fue el ejército uno de los elementos decisivos que permitieron a Filipo y su hijo Alejandro, bajo una coyuntura adecuada, imponer su supremacía en el entramado de las poleis griegas y en todo el Imperio Persa.

105 Con el apoyo de pequeñas unidades ligeras del tipo de los agrianes o los arqueros en flancos, avanzadillas, apertura del ataque... Infanteria ligera que ya utilizaba Filipo a gran escala. 